\title{
Role of Endoscopic Ultrasound in Diagnosis of Rectal and Perirectal Lesions
}

\author{
Zainab G Mahran ${ }^{1}$, Sherif Ibrahim Kamel ${ }^{1}$, Hussein Hassan Okasha ${ }^{2}$, \\ Ahmed M. Ashmawy ${ }^{3}$, Mohammed Ezz-Eldin ${ }^{1}$ \\ ${ }^{1}$ Department of Tropical Medicine and Gastroenterology, Faculty of Medicine, Assiut \\ University, Assiut, Egypt. \\ ${ }^{2}$ Department of Internal Medicine, Division of Gastroenterology, Kasr Al-Aini School \\ of Medicine, Cairo University, Cairo, Egypt. \\ ${ }^{3}$ Gastroenterology and Hepatology Unit, Department of Internal Medicine, Faculty of \\ Medicine, Assiut University, Assiut, Egypt.
}

Corresponding Author Mohammed Ezz-Eldin.

Mobile: +201018590854

E mail:

m.ezz@aun.edu.eg

Key words: Elasticity imaging Techniques, Endosonography, Rectum, Biopsy, FineNeedle .
Background and study Aim: Endoscopic ultrasound (EUS) demarcates several layers of the gastrointestinal wall, with little reports about its use as a diagnostic modality for rectal and perirectal lesions. So, we aimed to evaluate its role in diagnosis of rectal and perirectal lesions.

Patients and Methods: During the period between 2017 and 2019, a crosssectional study was done. Seventy adult patients included in the study who had rectal and/or perirectal lesions. All the 70 patients had rectal EUS. Out of the 70 patients, EUS-FNA was performed for 26 patients where it was possible and the wall was thick enough to allow for sampling $(>7 \mathrm{~mm})$

\section{INTRODUCTION}

Because of its capability to discriminate multiple layers of the gastrointestinal (GI) wall, endoscopic ultrasound (EUS) has become a valuable tool for evaluating GI tract lesions and lesions near the GI tract. Although EUS is well-known for assessing pancreatic and upper GI tract lesions, its value as a diagnostic and staging tool for other parts of the GI tract, notably the recto-sigmoid colon, is becoming more frequently recognized [1, 2].

Even though EUS can correctly stage GI malignancies, it cannot reliably distinguish benign from malignant lesions on its own. As a result, pathologic testing is usually necessary to establish a definitive diagnosis for
Results: Mean age of the study population was $51.91 \pm 9.90$ years, with a range of age between 26 and 69 years. There was a perfect agreement (Kappa Agreement $=1$ ) with statistically significant difference between EUS diagnosis, EUS-FNA diagnosis and final diagnosis. There was a perfect agreement (Kappa Agreement $=0.97$ ) with statistically significant difference between presumptive diagnosis and final diagnosis. Our study showed a relationship between EUS elastography and the final diagnosis of the lesions where soft pattern corresponded to most of the benign cases $(67.60 \%)$ and firm pattern corresponded to most of the malignant cases $(78.70 \%)$.

Conclusion: EUS is a useful diagnostic tool for rectal and perirectal lesions .

clinical intervention [3]. The ability to collect cytological material under direct vision has expanded the diagnostic performance of this procedure, allowing for a more precise diagnosis $[\mathbf{4}, \mathbf{5}]$.

Endoscopic ultrasound-guided fine needle aspiration (EUS-FNA) diagnostic accuracy for esophageal, gastric and duodenal subepithelial tumors has been reported to be $82-$ $94 \% \quad[6,7]$ and $80-95 \%$ for pancreaticobiliary lesions $[\mathbf{8}, \mathbf{9}]$.

Few studies have looked at how useful EUS is as a diagnostic tool for rectal and perirectal pathologies. The relevance of EUS-FNA in assessing submucosal and extrinsic masses of the colon and rectum has been highlighted in several trials [10-13]. 
Aim:

Our study looked at role of EUS to assess nature of polyps and submucosal lesions and differentiate benign and malignant lesions in the rectal and perirectal areas.

\section{PATIENTS AND METHODS}

This cross-sectional prospective study included 70 adult patients (44 males and 26 females) with mean age of $51.91 \pm 9.90$ years and ranges from of 26 to 69 years. All patients had rectal and/or perirectal lesions detected either by abdominopelvic CT or MRI and/or colonoscopy. All the 70 patients underwent rectal EUS. Out of the 70 patients, EUS-FNA was performed for 26 patients if the wall thickness was sufficient for aspiration $(>7 \mathrm{~mm})$. The patients selected from those attending the Internal Medicine Department during the period from June 2017 to May 2019.

In this study, inclusion criteria according to the findings detected were:

- Patients with a thickened rectal wall

- Patients with space occupying mass in the rectum or perirectal area

- Patients with rectal polyps

- Patients with rectal submucosal lesions

Exclusion criteria were:

- Patients with lesions more distant than $20 \mathrm{~cm}$ from the anal verge

- Patients with advanced co-morbidities (Chest, Heart diseases .... etc.) interfering with performing endoscopy or giving Propofol injection.

- Patients with bleeding tendency contraindicated EUS-FNA.

- Patients missed for following up or patients whose histological examination was not available, so the final diagnosis was not settled.

For all the patients included, the following assessment schedule applied:

- Detailed history taking with special stress on symptoms of bleeding per rectum, change in bowel habits, rectal pain, weight loss, anemic manifestations; history of similar conditions, previous operations or cancer; family history of similar conditions or cancer.

- Thorough clinical examination with special attention to abdominal examination (including per rectal examination) and lymph nodes examination.

- Abdominal ultrasound examination

- Thorough examination of recent abdominopelvic CT or MRI, as well as a colonoscopy for rectal or perirectal abnormalities, was performed prior to the EUS procedure. Patients were fasting for at least 8 hours before examination. Preparation done by polyethylene glycol and repeated enemas. Coagulation profile of the patients was assessed. Sedation with Propofol indicated in irritable patients. Patients received single IV antibiotic injection of third generation cephalosporins before EUS-FNA.

\section{Procedure:}

The patients were in a left lateral decubitus position. An EUS linear array machine (Pentax EG-3830UT Echoendoscope) attached to a compatible ultrasound machine (Hitachi EUB 7000 or Avius) were used. One expert endosonographer performed all EUS examinations. FNA was obtained under EUS guidance using fine needles (Cook Echotip needle) 22 or $19 \mathrm{G}$.

Elastography was done to assess the hardness of the lesions. To avoid puncturing intervening blood vessels, Doppler was utilized to assess the needle's predicted route.

During EUS, all lesions were examined thoroughly including all layers of the rectal wall underneath the lesions. The presence of perirectal lymph nodes, depth of wall invasion and invasion into the perirectal fat or adjacent organs (such as the bladder, prostate, seminal vesicles, vagina or anal sphincters) were evaluated (figure 1).

If it was feasible and the wall thickness was sufficient for aspiration, the FNA needle was progressed through the linear array echoendoscope's instrument channel, the gut wall punctured, the needle entered the lesion and reciprocated back and forth with a negative suction applied via a syringe of $10 \mathrm{~mL}$ once the internal stylet was removed. The needle was retracted then into the sheath before being removed from the scope. 


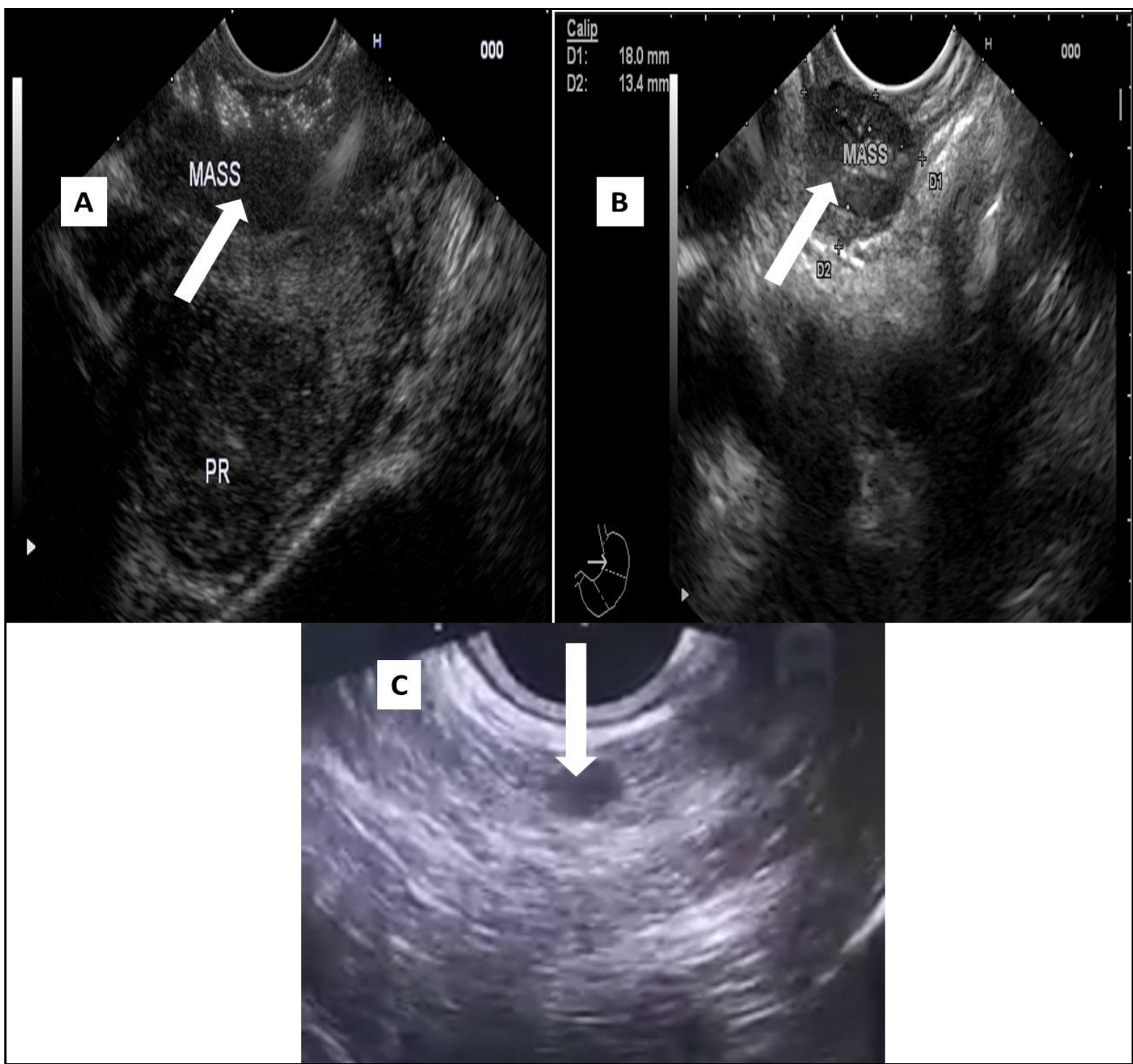

Figure 1: Rectal endoscopic ultrasound of some of the studied cases. A) rectal mass (white arrow) and cytopathology revealed adenocarcinoma, B) rectal mass (white arrow) with cytopathology revealed gastrointestinal stromal tumor, C) perirectal lymph node (white arrow).

PR, prostate.

The internal stylet was introduced and the tissue material was extracted onto a slide using air injected with a syringe. The needle was pushed through the lesion once more after checking that the tissue material was sufficient. The procedure repeated for 1-4 times to provide sufficient samples.

\section{Processing of cytological samples:}

All cytological samples are processed and interpreted by experienced cytopathologists. The specimens were considered satisfactory when it contained an adequate population of representative cells. The aspirated samples expelled onto slides, and smears prepared. Then the remaining specimens, obtained from subsequent passing, were processed for cellblock evaluation.

\section{Outcome:}

The percentage of patients who had a proper diagnosis using EUS and cytopathological diagnosis from samples collected by EUS-FNA were measured. Before undergoing EUS, a presumptive diagnosis was determined based on the imaging and colonoscopy data. In patients who have had surgery, the final diagnosis was made based on cytopathological findings from 
resected specimens. Based on the long-term clinical course (at least six months) as well as the EUS-FNA results, the final diagnosis was reached in patients who did not have surgery.

\section{Statistical Analysis:}

Data verified, coded by the researcher, and analyzed using IBM-SPSS 21. Descriptive statistics: Means, standard deviations, medians, ranges, and percentages calculated. Test of significance: chi-square test used to compare the difference in distribution of frequencies among different groups. Kappa agreement calculated to explore the validity of the different diagnostic modalities against the final diagnosis where; a kappa of 0.01-0.20 = no/slight agreement, 0.21$0.40=$ fair agreement, $0.41-0.60=$ moderate agreement, $0.61-0.80=$ good agreement, $0.81-1=$ perfect agreement (14). A significant p-value was considered when it is equal or less than 0.05 .

\section{RESULTS:}

\section{Demographics and Baseline Characteristics:}

Concerning medical history of studied cases, 50 $(71.40 \%)$ had rectal pain, $37(52.90 \%)$ had change in bowel habit, 40 (57.10\%) had bleeding per rectum, $7(10 \%)$ had weight loss, 33 (47.10\%) had anemic manifestations, 3 (4.30\%) had past history of cancer and $6(8.60 \%)$ had family history of cancer (table 1).

Concerning diagnosis made by colonoscopy of all the studied cases $(\mathrm{N}=70)$, six $(8.60 \%)$ were normal, $29(41.40 \%)$ were benign and $35(50 \%)$ were malignant.

About presumptive diagnosis (imaging + colonoscopy) of all the studied cases $(\mathrm{N}=70)$, $33(47.10 \%)$ were benign and $37(52.90 \%)$ were malignant.

On the topic of EUS elastography of all lesions $(\mathrm{N}=70)$, the score was two in 25 cases (35.70\%), three in 13 cases $(18.60 \%)$ and four in 32 cases $(45.70 \%)$.

Regarding the final diagnosis and diagnosis made by EUS for all cases $(\mathrm{N}=70), 32(45.70 \%)$ were benign and $38(54.30 \%)$ were malignant (figure 2).
Regarding the final diagnosis and diagnosis made by EUS-FNA for the selected cases (for whom FNA was done, $\mathrm{N}=26$ ), five cases (19.20\%) were benign, and 21 cases $(80.80 \%)$ were malignant (figure 3).

\section{Validity of Various Diagnostic Tools for Diagnosis of Malignancy:}

Regarding the validity of the EUS for diagnosis of malignancy in all studied cases $(\mathrm{N}=70)$, there was a perfect agreement (Kappa Agreement $=1$ ) with statistically significant difference $(\mathrm{P}<$ 0.001 ) between EUS diagnosis and final diagnosis (table 2 and 6).

About the validity of the EUS-FNA for diagnosis of malignancy in the selected cases $(\mathrm{N}=26)$, there was a perfect agreement (Kappa Agreement $=1)$ with statistically significant difference $(\mathrm{P}<$ 0.001 ) between EUS-FNA diagnosis and final diagnosis (table 3 and 6).

Regarding the validity of the colonoscopy for diagnosis of malignancy in all studied cases $(\mathrm{N}=$ 70), there was a perfect agreement (Kappa Agreement $=0.91$ ) with statistically significant difference $(\mathrm{P}<0.001)$ between colonoscopy diagnosis and final diagnosis with some disagreement (table 4 and 6).

About validity of the presumptive diagnosis (colonoscopy + imaging) for diagnosis of malignancy in all studied cases $(\mathrm{N}=70)$, there was a perfect agreement (Kappa Agreement $=$ $0.97)$ with statistically significant difference $(\mathrm{P}<$ 0.001 ) between presumptive diagnosis and final diagnosis with little disagreement (table 5 and 6).

\section{Relationship between EUS Elastography and the Final Diagnosis:}

As regards to the relationship between EUS elastography and the final diagnosis, 25 cases (35.70\%) of benign lesions had score 2, seven cases $(10 \%)$ of benign lesions and six cases $(8.60 \%)$ of malignant lesions had score 3 and 32 cases $(45.70 \%)$ of malignant lesions had score 4 with statistically significant difference $(\mathrm{P}<$ 0.001) (table 7). 
Table (1): Demographic characteristics and medical history of the studied cases.

\begin{tabular}{|l|c|c|}
\hline Variable & Category & $\mathbf{N}=\mathbf{7 0}(\boldsymbol{\%})$ \\
\hline \multirow{2}{*}{ Age/Years } & Mean \pm SD & $51.91 \pm 9.90$ \\
\cline { 2 - 3 } Sex & Median (Range) & $53(26-69)$ \\
\cline { 2 - 3 } Rectal Pain & Male & $44(62.90)$ \\
\hline Bowel Habit Change & Female & $26(37.10)$ \\
\hline Bleeding per Rectum & Yes & $50(71.40)$ \\
\hline Weight Loss & Yes & $37(52.90)$ \\
\hline Anemic Symptoms & Yes & $40(57.10)$ \\
\hline Past History of Cancer & Yes & $7(10)$ \\
\hline Family History of Cancer & Yes & $33(47.10)$ \\
\hline Noy & Yes & $3(4.30)$ \\
\hline
\end{tabular}

Note: Data expressed in the form of frequency (percentage) or mean (standard deviation) as appropriate.

$\mathrm{N}$, number; SD, standard deviation.

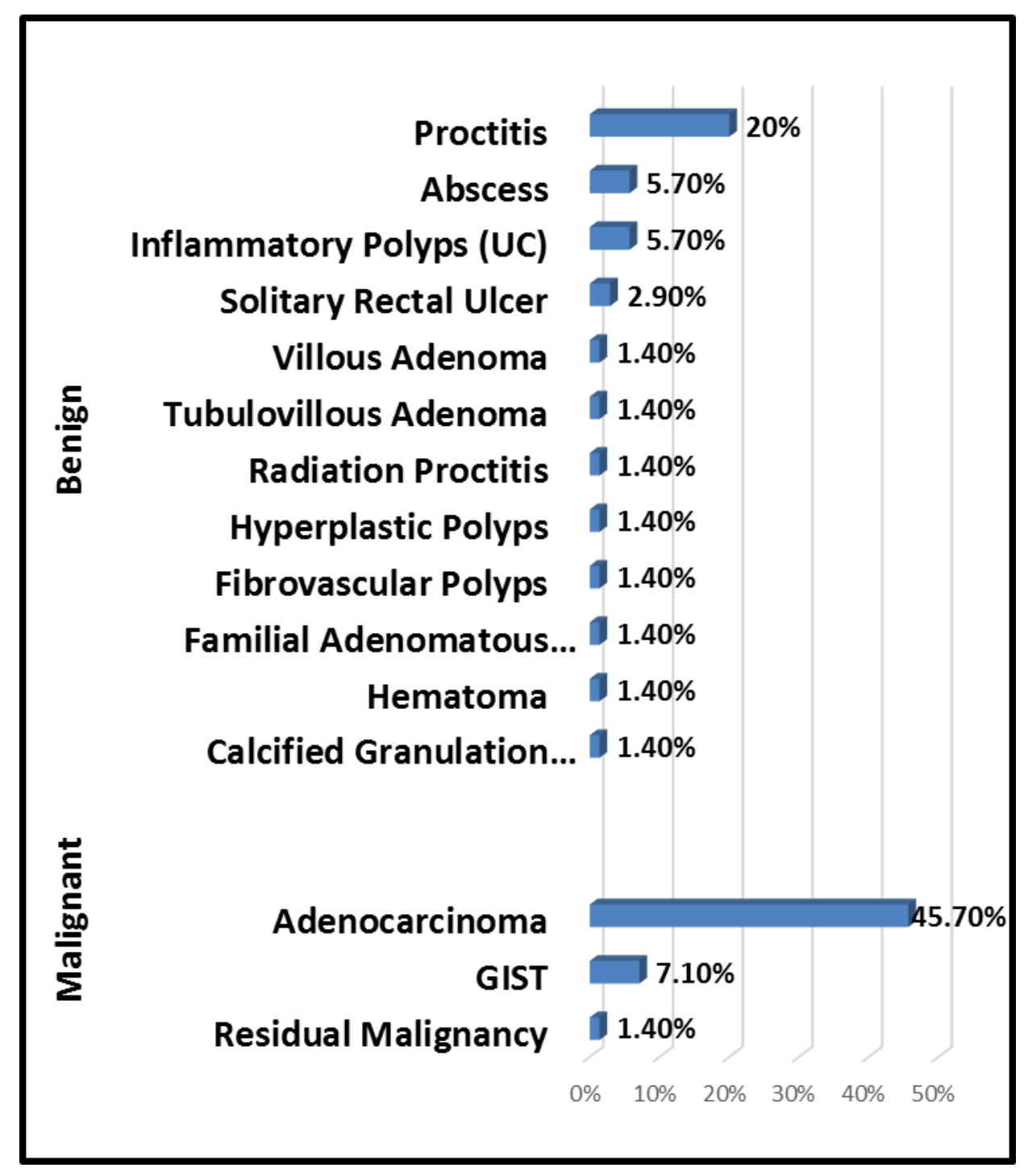

Figure 2: Final diagnosis of all studied cases according to disease nature.

GIST, gastrointestinal stromal tumor; UC, ulcerative colitis. 


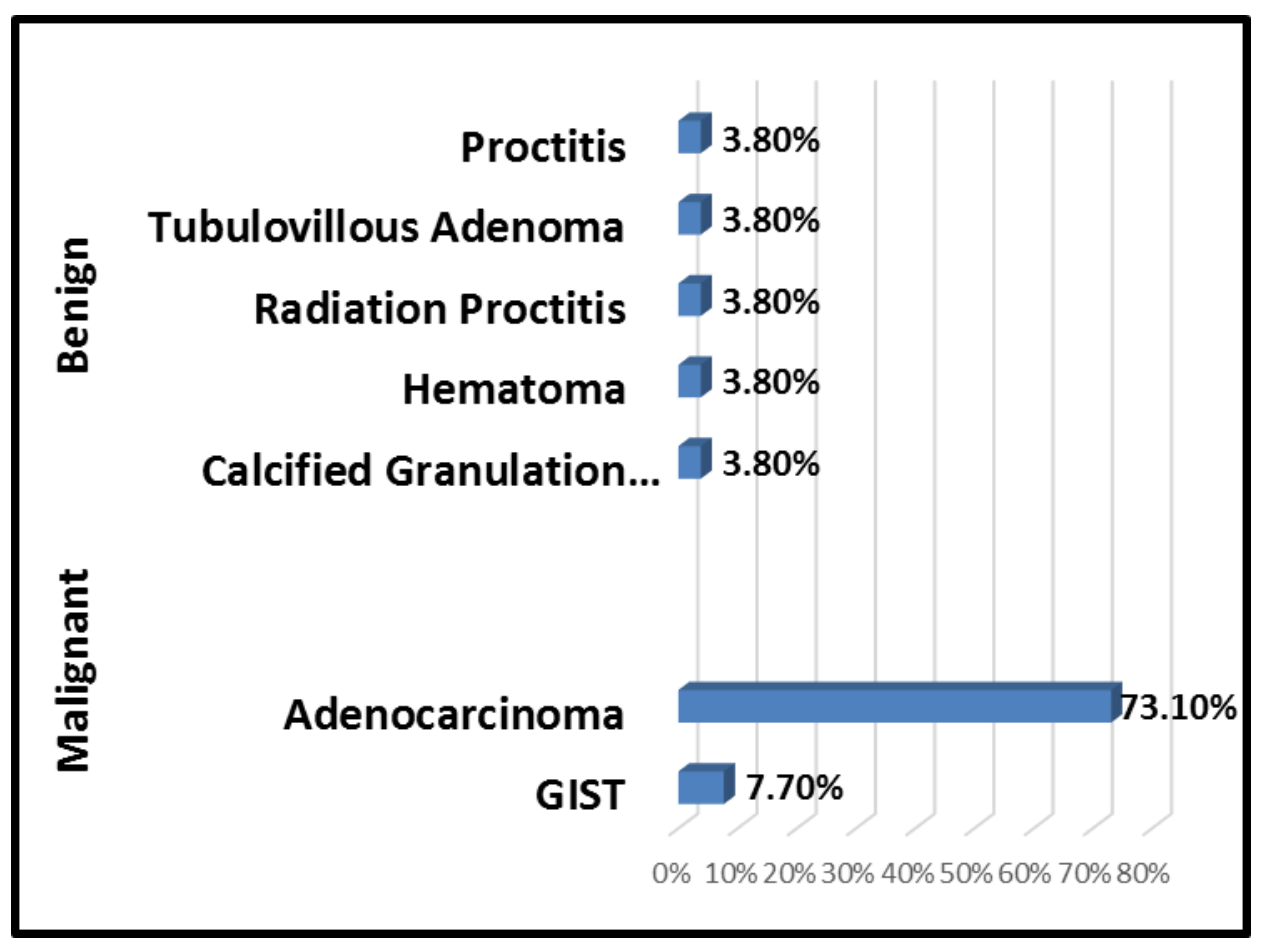

Figure 3: Final diagnosis of the selected cases according to disease nature.

GIST, gastrointestinal stromal tumor.

Table (2): Validity of the EUS for diagnosis of malignancy.

\begin{tabular}{|l|c|c|c|c|}
\hline \multirow{2}{*}{ EUS Diagnosis } & \multicolumn{3}{|c|}{ Final Diagnosis (\%) } & \multirow{2}{*}{ Total (\%) } \\
\cline { 2 - 5 } & & Benign & Malignant & \\
\hline Total & Benign & $32(45.70)$ & 0 & $32(45.70)$ \\
\cline { 2 - 5 } & Malignant & 0 & $38(54.30)$ & $38(54.30)$ \\
\hline Kappa Agreement & $32(45.70)$ & $38(54.30)$ & $70(100)$ \\
\hline Chi-square test & \multicolumn{2}{|c|}{$\mathbf{1}$} & $\mathbf{P}<\mathbf{0 . 0 0 1}$ \\
\hline
\end{tabular}

Note: Data expressed in the form of frequency (percentage) as appropriate.

A significant p-value was considered when it is equal or less than 0.05 .

A kappa of 0.01-0.20 = no/slight agreement, $0.21-0.40=$ fair agreement, $0.41-0.60=$ moderate agreement, 0.61 $0.80=$ good agreement, $0.81-1=$ perfect agreement.

EUS, endoscopic ultrasound.

Table (3): Validity of the EUS-FNA for diagnosis of malignancy.

\begin{tabular}{|c|c|c|c|c|}
\hline & \multicolumn{3}{|c|}{ Final Diagnosis (\%) } & \multirow{2}{*}{ Total $(\%)$} \\
\hline & & Benign & Malignant & \\
\hline \multirow{2}{*}{ EUS-FNA Diagnosis } & Benign & $5(19.20)$ & 0 & $5(19.20)$ \\
\hline & Malignant & 0 & $21(80.80)$ & $21(80.80)$ \\
\hline \multicolumn{2}{|l|}{ Total } & $5(19.20)$ & $21(80.80)$ & $26(100)$ \\
\hline \multicolumn{2}{|l|}{ Kappa Agreement } & \multicolumn{2}{|c|}{1} & $P<0.001$ \\
\hline \multicolumn{2}{|l|}{ Chi-square test } & & 6 & $P<0.001$ \\
\hline
\end{tabular}

Note: Data expressed in the form of frequency (percentage) as appropriate.

A significant $\mathrm{p}$-value was considered when it is equal or less than 0.05 .

A kappa of 0.01-0.20 = no/slight agreement, $0.21-0.40=$ fair agreement, $0.41-0.60=$ moderate agreement, $0.61-$ $0.80=$ good agreement, $0.81-1=$ perfect agreement.

EUS-FNA, endoscopic ultrasound-guided fine needle aspiration. 
Table (4): Validity of the colonoscopy for diagnosis of malignancy.

\begin{tabular}{|l|c|c|c|c|}
\hline \multirow{2}{*}{} & \multicolumn{3}{|c|}{ Final Diagnosis (\%) } & \multirow{2}{*}{ Total (\%) } \\
\cline { 2 - 5 } & & Benign & Malignant & \\
\hline \multirow{3}{*}{ Colonoscopy Diagnosis } & Normal & $4(5.70)$ & $2(2.90)$ & $6(8.60)$ \\
\cline { 2 - 5 } & Benign & $28(40)$ & $1(1.40)$ & $29(41.40)$ \\
\cline { 2 - 5 } & Malignant & 0 & $35(50)$ & $35(50)$ \\
\hline Total & $32(45.70)$ & $38(54.30)$ & $70(100)$ \\
\hline Kappa Agreement & \multicolumn{2}{|c|}{$\mathbf{0 . 9 1}$} & $\mathbf{6 0 . 7 3}$ & $\mathbf{P}<\mathbf{0 . 0 0 1}$ \\
\hline
\end{tabular}

Note: Data expressed in the form of frequency (percentage) as appropriate.

A significant p-value was considered when it is equal or less than 0.05 .

A kappa of 0.01-0.20 = no/slight agreement, $0.21-0.40=$ fair agreement, $0.41-0.60=$ moderate agreement, $0.61-$

$0.80=$ good agreement, $0.81-1=$ perfect agreement.

Table (5): Validity of the presumptive diagnosis (Imaging + Colonoscopy) for diagnosis of malignancy.

\begin{tabular}{|c|c|c|c|c|}
\hline & \multicolumn{3}{|c|}{ Final Diagnosis (\%) } & \multirow{2}{*}{ Total $(\%)$} \\
\hline & & Benign & Malignant & \\
\hline \multirow{2}{*}{$\begin{array}{l}\text { Presumptive Diagnosis (Imaging } \\
+ \text { Colonoscopy) }\end{array}$} & Benign & $32(45.70)$ & $1(1.40)$ & $33(47.10)$ \\
\hline & Malignant & 0 & $37(52.90)$ & $37(52.90)$ \\
\hline \multicolumn{2}{|l|}{ Total } & $32(45.70)$ & $38(54.30)$ & $70(100)$ \\
\hline \multicolumn{2}{|l|}{ Kappa Agreement } & \multicolumn{2}{|c|}{0.97} & $P<0.001$ \\
\hline \multicolumn{2}{|l|}{ Chi-square test } & \multicolumn{2}{|c|}{66.09} & $P<0.001$ \\
\hline
\end{tabular}

Note: Data expressed in the form of frequency (percentage) as appropriate.

A significant $p$-value was considered when it is equal or less than 0.05 .

A kappa of 0.01-0.20= no/slight agreement, $0.21-0.40=$ fair agreement, $0.41-0.60=$ moderate agreement, $0.61-$

$0.80=$ good agreement, $0.81-1=$ perfect agreement.

Table (6): Performance characteristics of various diagnostic tools for diagnosis of malignancy.

\begin{tabular}{|l|c|c|c|c|c|}
\hline \multicolumn{1}{|c|}{ Tool } & $\begin{array}{c}\text { Sensitivity } \\
(\%)\end{array}$ & $\begin{array}{c}\text { Specificity } \\
(\%)\end{array}$ & $\begin{array}{c}\text { Positive } \\
\text { Predictive Value } \\
(\%)\end{array}$ & $\begin{array}{c}\text { Negative } \\
\text { Predictive Value } \\
(\%)\end{array}$ & $\begin{array}{c}\text { Accuracy } \\
(\%)\end{array}$ \\
\hline EUS & $\mathbf{1 0 0}$ & $\mathbf{1 0 0}$ & $\mathbf{1 0 0}$ & $\mathbf{1 0 0}$ & $\mathbf{1 0 0}$ \\
\hline EUS-FNA & $\mathbf{1 0 0}$ & $\mathbf{1 0 0}$ & $\mathbf{1 0 0}$ & $\mathbf{1 0 0}$ & $\mathbf{1 0 0}$ \\
\hline Colonoscopy & $\mathbf{9 2}$ & $\mathbf{1 0 0}$ & $\mathbf{1 0 0}$ & $\mathbf{9 1 . 4 0}$ & $\mathbf{9 5 . 7 0}$ \\
\hline $\begin{array}{l}\text { Presumptive Diagnosis } \\
\text { (Imaging + Colonoscopy) }\end{array}$ & $\mathbf{9 7 . 4 0}$ & $\mathbf{1 0 0}$ & $\mathbf{1 0 0}$ & $\mathbf{9 7}$ & $\mathbf{9 8 . 6 0}$ \\
\hline
\end{tabular}

Note: Data expressed in the form of percentage as appropriate.

EUS, endoscopic ultrasound; EUS-FNA, endoscopic ultrasound-guided fine needle aspiration.

Table (7): Relationship between EUS elastography and final diagnosis.

\begin{tabular}{|l|c|c|c|c|}
\hline & \multicolumn{3}{|c|}{ Final Diagnosis (\%) } & \multirow{2}{*}{ Total (\%) } \\
\cline { 2 - 5 } & & Benign & Malignant & $25(35.70)$ \\
\hline \multirow{3}{*}{ EUS Elastography } & $\mathbf{2}$ & $25(35.70)$ & 0 & $13(18.60)$ \\
\cline { 2 - 5 } & $\mathbf{3}$ & $7(10)$ & $6(8.60)$ & $32(45.70)$ \\
\cline { 2 - 5 } Total & $\mathbf{4}$ & 0 & $32(45.70)$ & $70(100)$ \\
\hline Chi-square test & \multicolumn{3}{|c|}{$\mathbf{5 6 . 9 8}$} & $\mathbf{P}<\mathbf{0 . 0 0 1}$ \\
\hline
\end{tabular}

Note: Data expressed in the form of frequency (percentage) as appropriate.

A significant p-value was considered when it is equal or less than 0.05 .

EUS, endoscopic ultrasound. 


\section{DISCUSSION}

Although EUS may be used to outline the GI wall, there has been few research on the use of EUS to diagnose rectal and perirectal pathologies. As a result, rectal EUS continues to be underused, maybe due to a lack of knowledge and awareness of the procedure's worth.

Our study aimed to confirm the utility of EUS in the diagnosis of rectal and perirectal lesions. Rectal EUS and EUS-FNA, according to our findings, are excellent diagnostic techniques that play an important role in patient care. When a malignant diagnosis is made in a clinically worrisome lesion, treatment can begin right once. Unwarranted surgery can be avoided by confirming a benign diagnosis on lesions with low clinical suspicions.

Our study showed that both rectal EUS and EUSFNA had a perfect diagnostic accuracy, sensitivity and specificity, whereas colonoscopy alone had a lower diagnostic accuracy of $88.50 \%$, sensitivity of $88 \%$ and specificity of $89 \%$ because it missed some benign and malignant pararectal lesions. The diagnostic accuracy was improved to $93 \%$, the sensitivity to $97 \%$, and the specificity to $89 \%$ by adding an imaging modality to colonoscopy making a presumptive diagnosis.

Previous EUS studies for the lower GI tract have similarly shown great diagnostic precision. Boo et al. [13] found EUS to be effective in rectal or perirectal lesions, with good diagnostic accuracy (91.70\%). Amin et al. [15] found that EUS had a sensitivity and specificity of $91 \%$ and $100 \%$ for detecting malignant rectal/perirectal lesions, respectively. Maleki et al. [16] evaluated the use of rectal EUS to assess perirectal lesions and found that it had $87 \%$ sensitivity, $100 \%$ specificity, 90\% diagnostic accuracy, 100\% positive predictive value (PPV), and $77 \%$ negative predictive value (NPV). According to Puli et al. [17] meta-analysis and systematic review, the pooled sensitivity of EUS in diagnosing T0 was $97.30 \%$, the pooled specificity was $96.30 \%$, the positive likelihood ratio was 21.90 while the negative likelihood ratio was 0.08 .

Some previous trials have contradicted our findings. According to Soh et al. [18], EUS had a low diagnostic accuracy of 50\% for subepithelial tumors (5/10), 75\% for non-subepithelial tumors $(15 / 20)$, and an overall diagnostic accuracy of $67 \%(20 / 30)$ for rectal and perirectal lesion. And according to Serra-Aracil et al. [19], the overall accuracy of EUS was $78 \%$, with $83.78 \%$ sensitivity, $20 \%$ specificity, $91.30 \% \mathrm{PPV}$, and $11 \%$ NPV. Forty patients (8.08\%) were under staged, whereas $50(10.90 \%)$ were over staged.

The capacity to assess tissue elasticity makes elastography an extension of clinical sense, reinforcing and validating the diagnosis. There are, however, few research on the use of EUS elastography to distinguish benign from malignant rectal tumors. Our study showed that there was a relationship between EUS elastography and the final diagnosis of the lesions. Soft pattern (grades 1 and 2) corresponded to most of the benign cases $(67.60 \%)$ and firm pattern (grades 3 and 4 ) corresponded to most of the malignant cases $(78.70 \%)$.

Additional advantage of EUS is that it is quite safe, with a minimal risk of serious complications. In all the cases in which we studied it; the technique had no adverse effects.

Our work had some limitations; (1) Relatively small sample size (2) There were no on-site cytopathologists for all cases. (3) There was a problem in fixing specific imaging modality (e.g., MRI). (4) Restricted ability of rectal EUS examination to evaluate for the lymph nodes in the region of the left iliac vessels.

Various advanced technologies to enhance ultrasound imaging and therapeutic indications may contribute to the expanded utility of rectal EUS. Future multicenter studies with large sample sizes on the relevance of EUS and elastography in the evaluation of rectal and perirectal lesions are needed. Comparative studies between EUS and imaging techniques, particularly MRI, might be prepared in the diagnosis of rectal and perirectal lesions.

\section{CONCLUSION}

EUS is a useful diagnostic technique evaluating rectal and perirectal lesions; it confirms or rules out malignancy in lesions when clinical suspicion exists. On the condition that the endosonographer has a lot of expertise with endosonography, EUS alone without FNA may be enough to diagnose rectal and perirectal abnormalities. The use of EUS elastography in the identification and distinction of benign and 
malignant rectal and pararectal lesions could be valuable.

Source(s) of support: none

Presentation at meeting: no

Conflicting Interest: no

Ethical Considerations:

The study performed after being approved from the Institutional Review Board (IRB) of Faculty of Medicine with an IRB number of 17200593. The study was conducted in accordance with the provision of Declaration of Helsinki. Privacy of the participants as well as confidentiality of the data assured. Patients informed about the possible side effects and complications that may happen within the procedure. Informed consents, telephone numbers, and addresses were taken from the patients.

\section{Research highlights:}

- There was a perfect agreement and a perfect diagnostic accuracy between EUS or EUSFNA diagnosis and final diagnosis.

- There was an excellent agreement (with some disagreement) and low diagnostic accuracy between colonoscopy diagnosis and final diagnosis. But by adding an imaging modality to colonoscopy, making the presumptive diagnosis, the diagnostic accuracy was excellent.

- There was a relationship between EUS elastography and the final diagnosis of the lesions where soft pattern corresponded to most of the benign cases and firm pattern corresponded to most of the malignant cases.

- EUS alone without FNA may be sufficient for diagnosis of rectal and perirectal lesions on condition that high experience in endosonographgy.

\section{REFERENCES}

1. Chang KJ, Nguyen P, Erickson RA, Durbin TE, Katz KD. The clinical utility of endoscopic ultrasound-guided fine-needle aspiration in the diagnosis and staging of pancreatic carcinoma. Gastrointestinal Endoscopy. 1997;45(5):387-93.

2. Wiersema M, Vilmann P, Giovannini M, Chang K, Wiersema L. Endosonography-guided fineneedle aspiration biopsy: diagnostic accuracy and complication assessment. Gastroenterology. 1997;112(4):1087-95.
3. Sasaki Y, Niwa Y, Hirooka Y, Ohmiya N, Itoh A, Ando N, et al. The use of endoscopic ultrasoundguided fine-needle aspiration for investigation of submucosal and extrinsic masses of the colon and rectum. Endoscopy. 2005;37(02):154-60.

4. Knight CS, Eloubeidi MA, Crowe R, Jhala NC, Jhala DN, Chhieng DC, et al. Utility of endoscopic ultrasound-guided fine-needle aspiration in the diagnosis and staging of colorectal carcinoma. Diagnostic cytopathology. 2013;41(12):1031-7.

5. Anand D, Barroeta JE, Gupta PK, Kochman M, Baloch ZW. Endoscopic ultrasound guided fine needle aspiration of non-pancreatic lesions: an institutional experience. Journal of Clinical Pathology. 2007;60(11):1254-62.

6. Mekky MA, Yamao K, Sawaki A, Mizuno N, Hara K, Nafeh MA, et al. Diagnostic utility of EUS-guided FNA in patients with gastric submucosal tumors. Gastrointestinal Endoscopy. 2010;71(6):913-9.

7. Polkowski M. Endoscopic ultrasound and endoscopic ultrasound-guided fine-needle biopsy for the diagnosis of malignant submucosal tumors. Endoscopy. 2005;37(07):635-45.

8. Fisher L, Segarajasingam DS, Stewart C, Deboer WB, Yusoff IF. Endoscopic ultrasound guided fine needle aspiration of solid pancreatic lesions: performance and outcomes. Journal of Gastroenterology and Hepatology. 2009; 24(1):90-6.

9. Turner BG, Cizginer S, Agarwal D, Yang J, Pitman MB, Brugge WR. Diagnosis of pancreatic neoplasia with EUS and FNA: a report of accuracy. Gastrointestinal Endoscopy. 2010; 71(1):91-8

10. Chen V, Eloubeidi M. Endoscopic ultrasoundguided fine-needle aspiration of intramural and extraintestinal mass lesions: diagnostic accuracy, complication assessment, and impact on management. Endoscopy. 2005;37(10):984-9.

11. Honda K, Akahoshi K, Matsui N, Motomura Y, Kubokawa M, Higuchi N, et al. Role of EUS and EUS-guided FNA in the diagnosis of rectal implantation cyst at an anastomosis site after a previous low anterior resection for a rectal cancer without evidence of cancer recurrence. Gastrointestinal Endoscopy. 2008;68(4):782-5.

12. Gleeson FC, Clain JE, Rajan E, Topazian MD, Wang KK, Levy MJ. EUS-FNA assessment of extramesenteric lymph node status in primary rectal cancer. Gastrointestinal Endoscopy. 2011; 74(4):897-905. 
13. Boo S-J, Byeon J-S, Park DH, Seo DW, Yang D$\mathrm{H}$, Jung $\mathrm{KW}$, et al. EUS-guided fine needle aspiration and trucut needle biopsy for examination of rectal and perirectal lesions. Scandinavian Journal of Gastroenterology. 2011; 46(12):1510-8.

14. McHugh ML. Interrater reliability: the kappa statistic. Biochemia medica: Biochemia Medica. 2012; 22(3):276-82.

15. Amin K, Olyaee M, Tawfik O, Fan F. Endoscopic ultrasound-guided fine needle aspiration as a diagnostic and staging tool for rectal and perirectal lesions-an institutional experience. Ann Diagn Pathol. 2013;17(6):494-7.

16. Maleki Z, Erozan Y, Geddes S, Li QK. Endorectal ultrasound-guided fine-needle aspiration: a useful diagnostic tool for perirectal and intraluminal lesions. Acta Cytol. 2013;57(1):9-18.
17. Puli SR, Bechtold ML, Reddy JB, Choudhary A, Antillon MR. Can endoscopic ultrasound predict early rectal cancers that can be resected endoscopically? A meta-analysis and systematic review. Dig Dis Sci. 2010;55(5):1221-9.

18. Soh JS, Lee HS, Lee S, Bae J, Lee HJ, Park SH, et al. The clinical usefulness of endoscopic ultrasound-guided fine needle aspiration and biopsy for rectal and perirectal lesions. Intest Res. 2015;13(2):135-44.

19. Serra-Aracil X, Galvez A, Mora-Lopez L, Rebasa P, Serra-Pla S, Pallisera-Lloveras A, et al. Endorectal ultrasound in the identification of rectal tumors for transanal endoscopic surgery: factors influencing its accuracy. Surg Endosc. 2018; 32(6):2831-8. 